\title{
Tricuspid incompetence complicating acute myocardial infarction
}

\author{
P. Collins \\ M.D., M.R.C.P.
}

\author{
J. J. DALY
}

M.D., F.R.C.P.

The Royal Hospital, West Street, Sheffield

\begin{abstract}
Summary
A case of persistent tricuspid incompetence due to acute myocardial infarction is described. Review of the literature has revealed no similar case.

THE appearance of a systolic murmur for the first time during the course of acute myocardial infarction is common, often transient, and generally due to mitral incompetence (Heikkila, 1967). Less frequently, rupture of the interventricular septum is responsible (Holloway, Whalen and McIntosh, 1965).

A patient has recently been observed who developed a systolic murmur due to tricuspid incompetence on the eighth day following acute inferior myocardial infarction. The patient recovered and was in good health 1 year later, but with persistent signs of tricuspid incompetence. Review of the literature has revealed no similar case.
\end{abstract}

\section{Case report}

A 75-year-old woman was admitted with a 3-day history of central chest pain. Before this she had been treated for hypertension with methyldopa. No heart murmur was noted on previous medical examinations and there was no history of acute rheumatism. Examination revealed a regular heart rate of $50 / \mathrm{min}$ and a blood pressure of $85 / 50 \mathrm{mmHg}$. The apex beat was palpable in the fifth intercostal space in the anterior axillary line. There was no murmur on ausculation of the heart. The jugular venous pressure was elevated and crepitations were heard at the lung bases but there was no peripheral oedema. The ECG revealed junctional rhythm and acute, transmural, inferior myocardial infarction. The heart appeared enlarged on chest X-ray. Atrial fibrillation developed on the fourth day but there was no cardiac murmur. Digitalization was instituted with improvement. A pansystolic murmur, accentuated by inspiration, appeared on the eighth day together with prominent ' $V$ ' waves in the jugular venous pulse.

A chest X-ray at this time revealed pulmonary venous congestion without change in heart size or configuration from the initial X-ray. However, a third $\mathrm{X}$-ray taken three days later revealed marked increase

Correspondence: Dr P. Collins, The Royal Hospital, West Street, Sheffield S1 3SR.

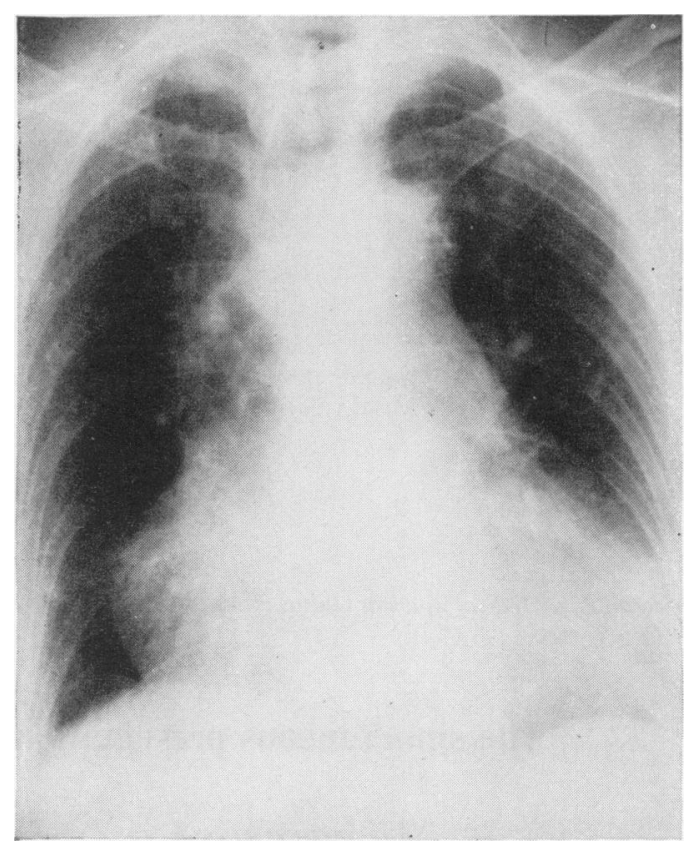

FIG. 1. Chest X-ray on admission.

in the size of the right atrium. There was no clinical radiologic evidence to suggest pulmonary embolism. The heart reverted spontaneously to sinus rhythm on the nineteenth day and she was discharged on the twenty-first day with persistent signs of tricuspid incompetence. When last seen, 1 year following the acute infarct, she was active and symptom free but the signs of tricuspid incompetence were present and screening of the heart revealed persistent but less prominent enlargement of the right atrium.

\section{Comment}

Review of the literature has revealed one previous case of tricuspid incompetence as a result of myocardial infarction due to a ruptured tricuspid papillary muscle (Eisenberg and Suyemoto, 1964). The patient did not survive. Heikkila (1967) mentioned the appearance of this complication in one of his patients, but no details were given. The extreme rarity of this complication is related to the infrequency of infarction of the right ventricle and to 


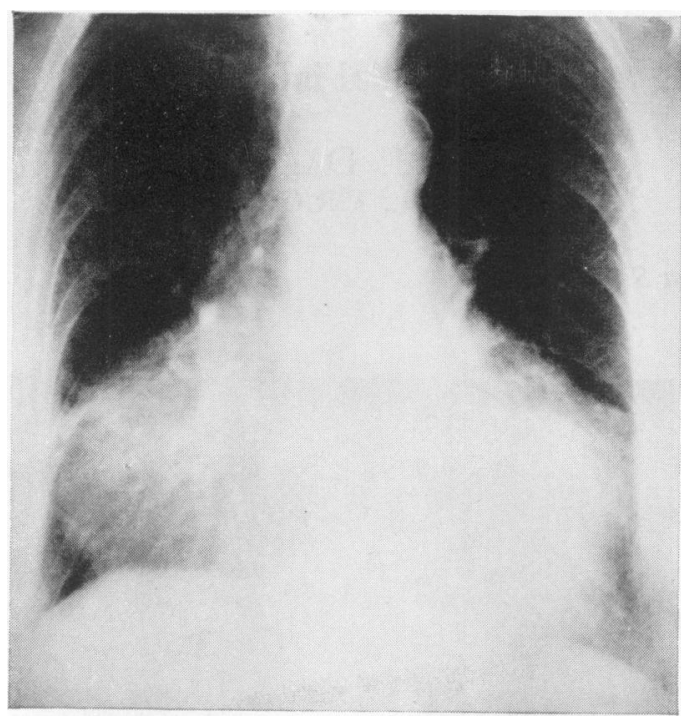

Fig. 2. Chest X-ray on the eleventh day, showing the development of right atrial enlargement. the fact that the three tricuspid valve leaflets generally receive chordal insertions from more than one group of papillary muscles (Eisenberg and Suyemoto, 1964). The course and clinical findings in the present patient point to papillary muscle dysfunction or rupture as the cause of tricuspid incompetence which developed in the course of acute myocardial infarction. This patient is unique in that she survived this rare complication of myocardial infarction but with persistent tricuspid incompetence.

\section{References}

Eisenberg, S. \& Suyemoto, J. (1964) Rupture of a papillary muscle of the tricuspid valve following acute myocardial infarction. Circulation, 30, 58.

HeikKILA, J. (1967) Mitral incompetence complicating acute myocardial infarction. British Heart Journal, 29, 162.

HeIKKILA, J. (1967) Mitral incompetence as a complication of acute myocardial infarction. Acta medica scandinavica, Suppl. 475.

Holloway, D.H., JR, Whalen, R.E. \& McIntosh, H.D. (1965) Systolic murmur developing after myocardial ischaemia or infarction. Journal of the American Medical Association, 191, 888.

\title{
The simultaneous presentation of Hodgkin's disease and myeloma
}

\author{
R. M. IBBOTSON* \\ M.B., M.R.C.P., M.R.C.Path. \\ E. A. Molland $\dagger$
M.A., M.B., B.Chir., M.R.C.Path.
}

P. A. ReVell $\dagger$

B.Sc., M.B., B.S., Ph.D.

M. J. MinTON*

M.B., M.R.C.P.

\section{Departments of *Haematology and $\nmid$ Morbid Anatomy, The London Hospital,} Whitechapel E1 IBB

\section{Summary}

The simultaneous presentation of Hodgkin's disease and multiple myeloma is described. This is rare as only one previous case appears to have been documented.

Speculations as to the aetiology are discussed as well as the significance of the presentation.

\section{Introduction}

Second malignancies develop in $1.6-2.2 \%$ (Cannellos et al., 1975) of patients with Hodgkin's disease following therapy. Multiple myeloma complicating treated Hodgkin's disease has been described (Rosner and Grunwald, 1974). A case is now reported in which these two neoplasms occurred simultaneously.

\section{Case report}

A 60-year-old male was admitted to a hospital with night sweats and weight-loss of 6 months' duration. An axillary lymph node biopsy revealed nodular sclerosing Hodgkin's disease. He was referred to The London Hospital and was staged 